\title{
Key Directions of Efficiency Improvement of Russian Taxation System
}

\author{
Bryantseva L.V.* \\ Chair of finance and credit \\ Voronezh State Agrarian University named after Emperor \\ Peter the Great \\ Voronezh, Russia \\ e-mail: blv2466@mail.ru
}

\author{
Orobinskaya I.V. \\ Chair of finance and credit \\ Voronezh State Agrarian University named after Emperor \\ Peter the Great \\ Voronezh, Russia
}

\author{
Pyltsina M.V. \\ Chair of constitutional and administrative law \\ Voronezh State Agrarian University named after Emperor Peter the Great \\ Voronezh, Russia
}

\begin{abstract}
The article discusses the tasks of improving the Russian taxation system, the main directions of improving its efficiency, as well as the main problems of the domestic tax system that require solution in the search for an effective taxation model. In the current Russian reality, the need to improve the system and methods of managing revenues of the federal budget of the Russian Federation under the crisis reduction of the sources and volumes of budget revenues is indisputable, which reduces the possibilities of financial support for socially important programs and is incompatible with the status of a social state. Obviously, compulsory payments are the core of the tax system. Different types of taxes are combined in the various tax systems in different ways. Being in search of an effective tax system, one should pay attention to the measures carried out by foreign countries that are currently in the similar crisis situation as Russia. Thus, the countries of the European Union and Oceania chose the way of increasing taxes on personal income, while the countries of North America resort to increasing taxes on corporations. For the Russian tax system, we can talk more about the introduction of a progressive tax scale, but not about a simple tax increase. For the business, tax systems used in the Middle East are becoming more applicable. In the conclusion of the work the main problems of the domestic tax system are highlighted that require solution in the search for an effective model of taxation.
\end{abstract}

Keywords - tax system, tax reformations, tax remissions, direct and indirect taxes, taxation optimization, social fairness.

\section{INTRODUCTION}

The Russian economy, which is currently in a recession, more than ever makes it necessary to choose an effective taxation system. This is due to the fact that, on the one hand, a social task is put forward that consists in optimization of the level of taxation of both individuals and legal entities, and on the other hand, no one can cancel the problem of achieving parity between revenues and expenditures of the state budget of the Russian Federation.
The taxation system is a specially organized set of its individual elements and the relationship between them. This interpretation of the tax system is quite broad. A similar interpretation is provided by the financial and credit encyclopedic dictionary. There the tax system is referred to as a set of taxes, principles, forms and methods for their establishment, cancellation and change, payment and application of measures to pay them, exercise of tax control, as well as prosecution and liability for violation of tax legislation.

\section{PROBLEM STATEMENT}

In the Russian academic literature it is possible to find many definitions of the tax system. For instance, some authors find difference between the concepts of "tax system", "system of the taxes" and "taxation system". It should be noted that the Tax Code of the Russian Federation [1] generally avoids the use of the term "tax system". We consider it necessary to use this term not only and not so much in the broad sense of the word, but also in a narrow one - as an organized set of various types of taxes, as well as institutions ensuring their functioning.

The modern Russian taxation system was formed in the early nineties of the 20th century. It is in operation since January 1, 1992, although it is still being optimized and improved. It was absolutely inevitable, since this tax system was taking shape in an incredible rush, due to the need to support market reforms and restructurization processes in the economy. As the tax structure operating under the command-administrative system did not in any way meet the requirements of the emerging market, it had to be radically transformed. The reference point in this case was the tax system of Western countries. However, as is well known, these systems are only homogeneous in their most general terms, while in details they differ to a considerable diversity, and only in a small approximation they met the requirements of an emerging, but not yet established market. Immediately it should be emphasized that the system of 
taxation in a market economy and in a mixed transitional economy can not be the same [2].

The introduction and putting into operation of the Tax Code of the Russian Federation marked a new stage in the formation of the current Russian tax system. The main task of the present day in the process of reforming the tax system is to increase its efficiency. Effective taxation system, in our opinion, is the system that assumes high degree of profitability with a sharp reduction in expenses associated with time, monetary and other expenses when collecting taxes.

The effective tax system implies its ability to attract investments in the country's economy and prevent capital outflows. The effective taxation system plays its special role now, when the task of ensuring import substitution, overcoming the low competitiveness of the Russian economy, reducing its rent-orientation is formulated.

When we evaluate the current tax system of the Russian Federation from the point of view of its efficiency, it is impossible not to notice the following problems:

- the ratio of the efficiency and social justice;

- the ratio of the taxation level for individuals and legal entities;

- disproportion in the level of taxation of the commodity sector and other sectors of the country's economy;

- the ratio of direct and indirect taxation;

- the ratio of progressive and proportional taxation;

- disparities in the amount of tax revenues at the federal, regional, and local levels [6].

Since the solution of these problems is the key point for the implementation of tax reform in Russia, we should consider them in more detail.

It is known that the tasks of achieving efficiency and social justice are mutually exclusive. Therefore it is quite difficult to increase the efficiency of taxation by raising the tax burden and to ensure high level of social justice by redistributing the tax burden between the rich and the poor at the same time $[3,4]$. Here it becomes necessary to achieve certain balance in the taxation of both individuals and legal entities. It seems indisputable that the taxation level for the income of legal entities, and their profits above all, can not be increased during a recession, especially when it comes to small and medium business. The simplified taxation model for small and medium-sized business obviously enhances social justice and at the same time does not reduce the tax system efficiency. As for the taxation of individuals, here the need to stimulate aggregate demand as the most important component of the Keynesian model of counter-cyclical regulation encourages reduction of the level of direct taxation of income due to some increase in the collection of indirect taxes. Indirect taxation can be increased not so much by increasing the tax rate on value added tax, for example from 18 to $20 \%$, but by increasing excise duties on the sale of excisable goods such as tobacco and alcohol, as well as by increasing import and export customs duties. Introduction of sales tax and fiscal monopoly tax can also play its role [5].

In the current recession in Russia, the number of Russians by the end of December 2017, living below the poverty line, whose incomes were below the subsistence minimum, is more than 20 million people. According to Russian national statistics service, the fall in real incomes of Russians approached the record of the 90s. Such growth in the poverty level is associated with the significant increase in the subsistence minimum per person per month and from May 1, 2018 the federal minimum wage in Russia is set at the subsistence minimum of the working-age population in Russia as a whole $-11,163$ rubles [6].

If we turn to direct taxation of individuals, the personal income tax can be charged not only on a flat, but also on a progressive scale. It should be borne in mind that people with low incomes consume predominantly low-level goods, the price elasticity of demand for which is low, so the demand on their part remains almost the same when the price rises due to indirect taxation. As for people with high incomes, they impose a demand for elite goods. This demand will increase as the price grows. Therefore, this category of taxpayers can, without prejudice to product demand, pay not only indirect taxes, but also the direct income tax on a progressive scale [7-10].

Over the past 4 years (since the beginning of 2014), the rates of indirect taxes have been revised by 13 countries, all upwards. 33 countries have changed corporate tax rates, two thirds of them - have lowered them. The most significant increase in corporate tax is found in Greece - from 20 to 26 $\%$ [11-12].

Recently, the issue of the tax burden for the wealthy citizens has been widely discussed in many countries.

In 2014, the BBC published a study by PWC, concerning how much of their income people can keep for themselves, if earning \$400,000 a year, after paying taxes and social contributions. It was assumed that the taxpayer is married, has 2 children and pays a mortgage loan of $\$ 1.2$ million. We have a single rate of $13 \%$ for all, and although initiatives to raise taxes for wealthy citizens appear regularly, the authorities still prefer not to consider this issue.

\section{AnAlysis}

It is necessary to note that today in Russia there is some imbalance between the level of taxation of the base material sector and other sectors of economy. This leads to a slowdown in the development of the manufacturing and service industries as a result of the reduction in the investment flow.

The analysis of economic cycles and recessions in 1998, 2008 and 2016 demonstrates close, direct proportion between the rate of growth or decline in GDP and the trend of changes in oil prices. The same dependence can be traced 
between the revenues of the consolidated budget and world oil prices. Thus, in the first half of 2016, the oil and gas revenues of the budget decreased by $45 \%$.

The analysis of upward or downward trends that historically existed in the oil market suggests that the upward wave of the 2000s, which led to the emergence of new production technologies (light tight oil), the emergence of new energy-saving technologies and products, alternative energy sources, etc., hardly gives hope for a sharp return to the price of one hundred dollars per barrel.

Tax incentives for the production of the final, nonresource production and small business is one of the most important tasks of today's reality.
From 2016 to 2017 , the number of small companies in Russia decreased from 232.4 to 172.9 thousand, that is, by 1.34 times. The employment rate in small and medium business in the Russian Federation is $17 \%$. This is the lowest value among the G20 countries. For example, in Germany this value is $59 \%$, in the USA - $47 \%$, in Brazil $34 \%$.

In order to ensure economic growth and financial stability as the main goal of economic development, the following tasks of improving the tax system should be solved (Figure 1).

\section{The tasks for the Russian tax system improvement}

to minimize the tax burden, which implies the establishment of a fair minimum possible level of tax burden, primarily on the processing industries and services, through the transformation of savings into investments, the restructuring of natural monopolies to access all their services at market prices

to improve the existing system of individual tax collection, for which it is necessary to clearly define the object of taxation, the tax base, the tax rate, the procedure forcalculating and paying tax

to improve the system of tax control and change the system of tax liability

Fig. 1. Tasks for the Russian tax system improvement

Being in search of an effective tax system, a country should pay attention to those measures carried out by foreign countries that remain in a similar crisis situation as Russia. Thus, the countries of the European Union and Oceania chose the way of increasing taxes on personal income, while the countries of North America resort to increasing taxes on corporations. As we have already noted, these schemes are unlikely to improve the taxation efficiency in their pure form. It could rather be the introduction of a progressive scale of taxation, not just a simple tax increase. For business, tax systems used in the Middle East are becoming more applicable.

Talking about global trends in the structure of taxation in 2016, it should be noted that the average global income tax rate increased by $0.5 \%$, while corporate income tax decreased by $0.1 \%$, while the level of indirect taxation remained almost unchanged [13-15]. to reform the system of distribution of tax revenves between the federal, regional and local levels of the budgetary system, which is particularly relevant today when, due to the simplification and reduction of taxation of small and medinm-sized business, tax revenves to regional budgets are sharply reduced compared to the federal one

to improve the tax administration system and increase the degree of liability for tax offenses

\section{taxation optimization}

In the medium term prospect, the main directions of improving the efficiency of the tax system of the Russian Federation should be as shown in Figure 2.

This is added to the fact that at present the world tax policy is focused on the neoconservative model of countercyclical regulation, proposed, in particular, by the American economist, theoretician of the supply economy A. Laffer. At the same time it seems to us, that in a crisis situation, the Keynesian counter-cyclical model of regulation would be preferable. This model applied to increasing the taxation efficiency over the past 4 years (from the beginning of 2014) was used by 13 countries, including Montenegro, which introduced progressive personal income tax instead of the 9-percent personal income tax, and the incomes over 720 euros per month are taxed $15 \%$.

In these 13 countries, indirect tax rates have been increased. 
However, to this day there are countries with a zero income tax rate. These are mainly countries of the Middle East and island jurisdictions. The only European country in which citizens do not pay income tax is Monaco, although this exemption does not apply to the French who settled in the principality before the end of the 1950s.

As for such direct tax, as the income tax, in the current financial crisis, there is a tendency to reduce it. Although the world average tax burden on business reaches $40.9 \%$ of profits, in 2015, with a total reduction in taxes per unit, the hours spent on their payment decreased by 4 , and the overall burden decreased by $1.3 \%$.
After the introduction of electronic document management the efficiency of taxation significantly increased, especially in Eastern Europe and Central Asia, where the tax burden decreased by almost $5 \%$, the number of payments - by 6 , and the time for them - by 11 hours.

It was necessary to point out that in almost all countries tax reforms are currently underway aimed at preventing tax evasion, capital outflows to offshore zones, and above all to Swiss banks. According to the International Consortium for Investigative Journalism (ICIJ) Russia ranks 27th place among countries whose citizens are suspected of avoiding taxes with the help of MSBC, a Swiss bank.

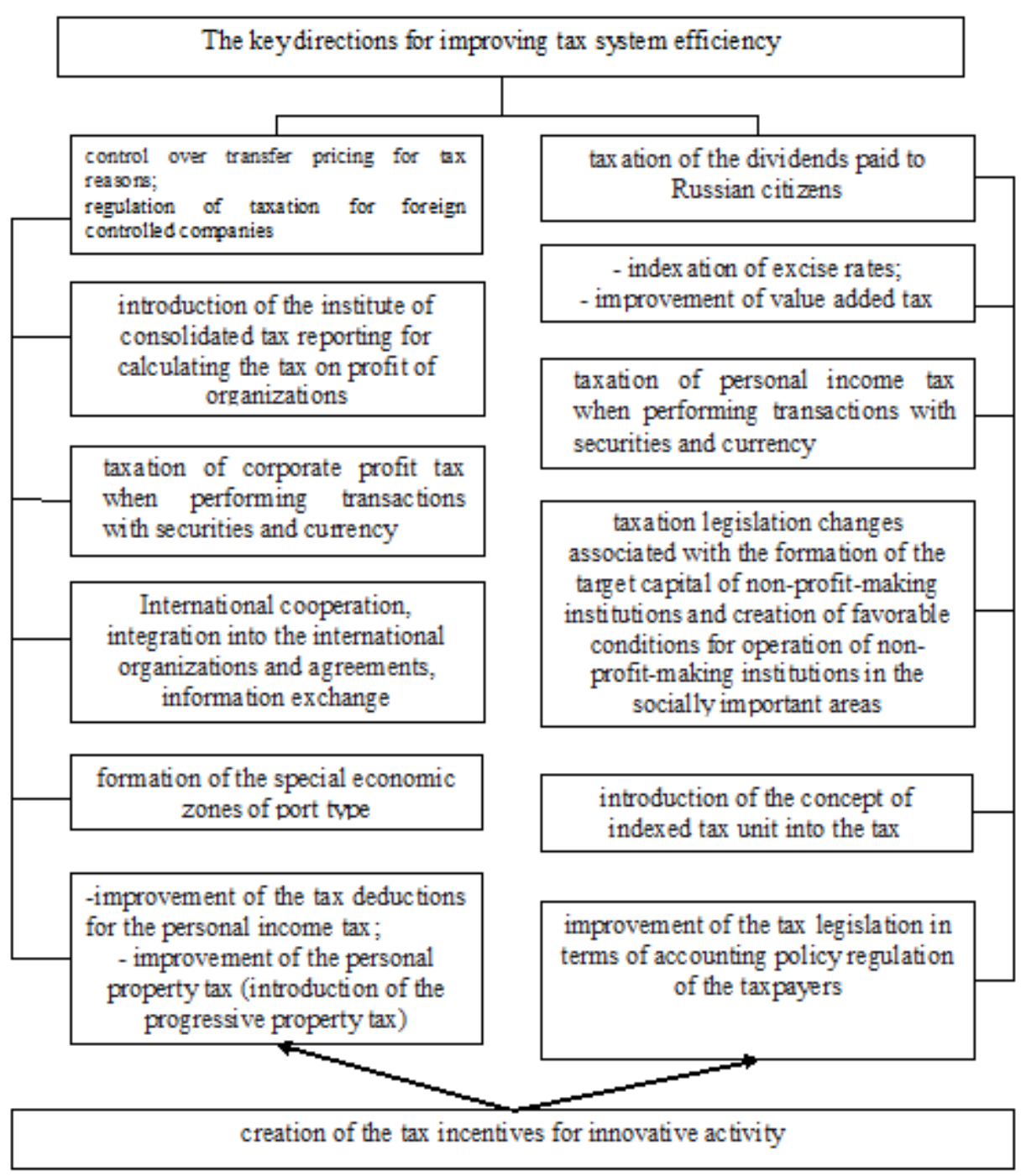

Fig. 2. Key directions for improving tax system efficiency

\section{CONCLUSION}

Summing up, it is necessary to identify the main problems of the our national tax system that require resolution in the search for an effective taxation model:
- instability of tax policy, which is especially noticeable under the combination of crisis phenomena in the economy and a fairly high level of inflation;

- excessive tax burden imposed on the taxpayer, especially in cases where direct taxation prevails over indirect taxation; 
- low level of tax collection and high level of insolvency of enterprises and citizens, associated with the decrease in living standards;

- excessive use of tax benefits, although recently their number has de-creased;

- lack of incentives for the development of the real sector of the economy;

- the effect of inflation taxation and the so-called TanziOliver effect, ex-pressed in the devaluation of tax revenues to the budget;

- excessive wage taxation;

- single tax rate for personal income;

- transfer of the main tax burden to industries;

- trend to increase the share of direct taxes;

- shadow economy and increasing outflow of capital abroad;

- imperfection of tax legislation.

\section{References}

[1] Tax Code of the Russian Federation (part 1): dated 31.07.1998 N146-Ф3 (version 01.05.2016) (with alterations and amend-ments dated 02.06.2016). Legal reference system Consultant Plus. Retrieved from: http://www.consultant.ru/document/cons_doc_LAW_19671/e34866eab0 f176df59d8c3620368c1465a7fd51c/

[2] N.K. Avkiran, C.M. Ringle, R. Low, "Monitoring transmission of systemic risk: application of partial least squares structural equation modeling in financial stress testing", J. of Risk, vol. 20, no. 5, pp. 83-115.

[3] M. Brewer, J. Browne, R. Joyce, "Child and working-age poverty from 2010 to 2020”, Commentary Instit. for Fiscal Studies, no. 121, 2011.
[4] A.S. Deaton, "Measuring poverty in a growing world (or measuring growth in a poor world)", Rev. of Econ. and Statist., vol. 87, no. 1, pp. 1-19, 2005.

[5] V.V. Khmelenko, "Comparative analysis of the advantages and deficiencies in collection of direct and indirect universal taxes", The issues of modern sci. and ed., vol. 12, no. 54, pp. 81-86, 2016.

[6] T.L. Bezrukova, L.V. Bryantseva, V.L. Pozdeev, I.V. Orobinskaya, A.G. Kazmin, B.A. Bezrukov, "Conceptual aspects of tax system development in cyclic economy", Contribut. to Econ., no. 9783319454610 , pp. 287-303, 2017.

[7] L. Zaporozhtseva, D. Kleimenov, E. Kuznetsova, A. Orekhov, Yu. Tkacheva, "Transformation of socio-economic development scenarios of russian rural areas in the context of globalization", IOP Conf. Ser. Earth and Environmental Sci. The proc. of the conf. AgroCON-2019, p. 0120292019.

[8] G.S. Epstein, I.N. Gang, "Taxation and social protection under governance decentralization", Europ. J. of Political Econ., vol. 60, no. 101743, 2019.

[9] K. Lee, "Absentee ownership, land taxation and surcharge", Annals of Reg. Sci., vol. 62, iss. 1, pp. 47-68, 2019.

[10] A.-S. Lafuite, G. Denise, M. Loreau, "Sustainable Land-use Management Under Biodiversity Lag Effects", Ecol. Econ., vol. 154, pp. 272-281, 2018.

[11] Emiliano Huet-Vaughn, Andrea Robbett, Matthew Spitzer, "A taste for taxes: Minimizing distortions using political preferences", J. of Public Econ., vol. 180, no. 104055, 2019.

[12] Robert Scherf, Matthew Weinzierl, "Underst(2019)anding Different Approaches to Benefit-Based Taxation", Fiscal Studies, 2019.

[13] J.M. Duke, T.H. Gao, "An Experimental Economics Investigation of the Land Value Tax: Efficiency, Acceptability, and Positional Goods", Land Econ., vol. 94, iss. 4, pp. 475-495, 2018.

[14] Joel Slemrod, "Tax Compliance and Enforcement", J. of Econ. Literat., vol. 57, iss. 4, pp. 904-954, 2019.

[15] K.A. Bannova, N.E. Aktaev, "Mathematical modelling of optimal tax trajectory within the framework of Cobb-Douglas model", Applied Economics Letters, 2019. 